\title{
Computer Based Model for Design Selection of Lightning Arrester for 132/33kV Substation
}

\author{
Uma U.Uma, I.K.Onwuka \\ Akanu Ibiam Federal Polytechnic Unwana \\ Micheal Okpara University Umudike
}

\begin{abstract}
Protection of equipment insulation against lightning over voltages and selection of lightning arrester that will discharge at lower voltage level than the voltage required to breakdown the electrical equipment insulation is examined. The objectives of this paper is to design a computer based model using standard equations for the selection of appropriate lightning arrester with the lowest rated surge arrester that will provide adequate protection of equipment insulation and equally have a satisfactory service life when connected to a specified line voltage in power system network. The effectiveness and non-effectiveness of earthing system of substation determines arrester properties. MATLAB program with GUI (graphic user interphase) its subprogram is used in the development of model for the determination of required parameters like voltage rating, impulse spark over voltage, power frequency spark over voltage, discharge current, current rating and protection level of lightning arrester of a specified voltage level of a particular line.
\end{abstract}

Keywords: - Lightning Arrester, GUIs, MatLab program.

\section{INTRODUCTION}

Transmission substation delivers bulk power from power stations to the centres and large industrial consumers beyond the economical service range of the regular primary distribution lines. The main components are the transformers, circuit breakers, current and voltage transformers etc. To protect these equipments from insulation breakdown, as result of over-voltage, over-currents, switching surges and lightning surges, an appropriate protection system must be in place.

Lightning [direct stroke and indirect stroke] is one of the major causes of insulation breakdown of equipment in power stations. This paper aims at describing a computer based model for the selection of lightning arrester for a $132 / 33 \mathrm{kV}$ substation. The arrester rated voltage are $116 \mathrm{kV}$ and $29 \mathrm{kV}$ The goal of this paper is to provide the designer of substation protection scheme with some general guidelines for the appropriate selection and application for lightning arresters.

\section{Lightning and Thunder}

An electric discharge between cloud and earth, between clouds or between the charge centers of the same cloud is known as lightning. It involves a huge spark and takes place when clouds are charged to such a high potential ie $+v e$ or $-v e$ with respect to earth or a neighbouring cloud that the dielectric strength of neighbouring medium [Air] is destroyed.The thunder which accompanies lightning is due to the fact that lightning suddenly heats up the air, thereby causing it to expand and the surrounding air pushes the expanded air back and front causing the wave motion of air.

\section{Lightning Discharge}

When a charged cloud moves over the earth, it induces equal and opposite charge on the earth. As the charge gain by the cloud increases, the potential between the cloud and earth increases with corresponding increase in the gradient of air. Break down of the surrounding air starts when the potential gradient is between $[5 \mathrm{kV} / \mathrm{cm}-10 \mathrm{kV} / \mathrm{cm}]$. Immediately the air near the cloud breaks down, Pilot Streamer starts from the cloud to the earth. The extent of travel which will be determine by supply of charge from the source in other to maintain a higher gradient at the tip of Leader Stream above the strength of air. Lower gradient will stop the movement and the charge dissipated without forming complete stroke. Maintenance of higher gradient will cause the streamer leader to make contact with the earth. When this leader contacts the ground an extremely bright return streamer propagetes upwards from ground to the cloud following the same path of the downward leader at a very rapid rate. Complete breakdown of insulation occurs at this point which leads to a sudden spark called lighting with neutralization of the charge on the cloud. 


\section{Relationship between lightning strokes and power system equipment}

Lightning strikes on power system [overhead lines, towers, substation] inject a high current into the system. This strike may be direct stroke or indirect stroke. For direct stoke the discharge is directly from the cloud to the line. The lightning current induced will be over the insulators down the pole to the ground, which if large enough causes flashover of the insulator thereby grounding the line while the indirect stroke is the major cause of surges in transmission line which is as a result of electrostatic induction between the charged cloud and the line.

\section{Lightning Arrester}

Lightning arrester are usually made up of resistor blocks which offers low resistance to high voltage surge and divert the high voltage surge to ground, thereby the insulation of protected installation is not subjected to the full surge voltage. It consists of silicon carbide or zinc oxide elements in series with gap elements. The gap unit consists of air gaps of approximate length. During normal voltages the surge arrester does not conduct. When a surge wave travelling along the line reaches the arrester, the gap breaks down. The resistance offered being low the surge is diverted to the earth. After a few $\mu$ seconds the surge vanishes and normal frequency voltage is set up across the arrester. The resistance offered by resistors to this voltage is very high. Therefore, arc current in gap units reduces and voltage across the gap is no more sufficient to maintain the arc. Therefore, the current flowing to the earth is automatically interrupted and normal condition is restored.

\section{Basic requirements of Lightning Arrester}

$>$ It should behave as a perfect insulator for the highest system voltage to ground.

$>$ It should discharge any over voltage into the ground safely

$>$ It should restore itself as an insulator after discharging the excess voltage.

The classification of lightning arrester

1. Distribution type

2. Line type

3. Station type

\section{EARTHING SYSTEM OF SUBSTATION}

Earthing means a connection to the general mass of earth. Earthing is so widespread in an electric system that practically every point in the system from the generating system to the consumers equipment earth connections are made. The main objective is to reduce the voltage stress due to switching and lightning surges by providing a path through which these excesses are discharge safely into the ground. In addition, in determing the arrester rating, attention should be given to the co-efficient of earthing which is defined as the ration of highest r.m.s voltage to earth of sound phase or phases at the point of application of arrester during a line to earth fault to the highest line to r.m.s voltage expressed as a percentage of the latter voltage. This coefficient of earthing is divided into effective earthed system and non effective earthed system. A system is said to be effectively earthed if under any fault condition, the line to earth voltage on the healthy phase/phases will not exceed $80 \%$ of the system line to line voltage while non effectively earthed system the voltage is more than $80 \%$ but less than $100 \%$ of the line to line voltage.

\section{Selection of Lightning Arrester}

The main aim in arrester application is to select the lowest rated lightning arrester that will provide adequate protection of the equipment insulation from burning and be rated in a way that it will have a satisfactory service life when connected to the power system. Lightning arresters are designed by the crest size of the discharge current having 10x20 $\mu$ second wave shape which the arrester can safely discharge without damage. The lightning arresters are rated as 5,10 and 20kA. Ratings of 10kA and above are specified for system voltages of $66 \mathrm{kV}$ and above. Ratings of $5 \mathrm{kA}$ are for system voltages of $11 \mathrm{kA}$ and below. They can safely discharge these current crests. Selection of lighting arrester with approximate rating is preferred because it provides the highest protective margin for the equipment. Higher arrester ratings will increase the ability of the arrester to survive on a specific line but reduce the protective margin between the arrester and the equipment .

\section{Steps taken when selecting lightning Arrester}

$>$ Calculation of the maximum line to ground dynamic overvoltage to which the arrester maybe subjected to for any condition of system operation.

$>$ Calculation of the maximum r.m.s line to ground voltage during a system fault.

$>$ Determination of the ratio $R_{o} / X_{i}$ and $X_{O} / X_{i}$ at the point of installation and also the co-efficient of earthing.

$>$ Make a tentative selection of the power frequency voltage rating of the arrester.

$>$ Determine the maximum arrester discharge voltage for the impulse current and type of arrester selected. 
$>$ Establish the full wave impulse voltage withstand level of the equipment to be protected.

$>$ Make certain that the maximum arresting discharge voltage is below the full wave impulse withstand level of the equipment insulation to be protected by an adequate margin.

$>$ Establish the separation limit between the arrester and the equipment to be protected.

\section{INSTALLATION OF LIGHTNING ARRESTER}

The best location for installation of lightning arrester is as close as possible to the equipment it is protecting, preferably at the terminals where the service is connected to the equipment. An approximate rule of thumb for the location of lighting arrester is shown in equation .

maximum distance in feet $=\frac{\text { Nominal system voltage in } \mathrm{kV}}{2}$

Conductor length for the connection of the lightning arrester to the equipment terminals and to ground should be minimized and installed as straight as possible, reducing bends in the conductors. This will ensure that the surge energies are drain to the earth quickly without affecting the equipment.

\section{Algorithm for Lightning Arrester Specification}

Step 1. Read in the field data: line voltage,frequency, effectiveness of earthing, basic insulation level (BIL)

Step 2. Calculate the voltage rating of arrester $\left(\boldsymbol{V}_{\boldsymbol{R}}\right)$ using equation(2)

$V_{R}=1.1 * 0.8 *$ Line voltage .......2

Step 3. Calculate the impulse spark over voltage ( $\left.\boldsymbol{I}_{\boldsymbol{M S V}}\right)$ using equation (3)

$I_{M S V}=3.6 * V_{R} \ldots \ldots \ldots \ldots \ldots \ldots . . . . . . .3$

Step 4. Calculate the power frequency spark over voltage $\left(\boldsymbol{P}_{\boldsymbol{F S}}\right)$ using quation(4)

$$
P_{F S}=1.6 * V_{R} \ldots \ldots \ldots \ldots \ldots . . . . . . .4
$$

Step 5 Determine the maximum discharge current $\left(\boldsymbol{I}_{\boldsymbol{a}}\right)$ using equation(5)

$$
I_{a}=\frac{2 e i-e_{a}}{Z} \ldots 5
$$

$e_{i}=$ voltage of a travelling wave

$e_{a}=$ residual voltage of the LA $z=$ surge impedance of the line

and select the nearest approximate value from table as the arrester current rating.

Step 6 Determine the protection level of a lightning arrester $\left(\boldsymbol{P}_{\boldsymbol{L A}}\right)$ using eq. (6)

$$
P_{L A}=1.25 * I_{M S V}
$$

and select the nearest approximate value

Step 7 Check if BIL is greater than $\boldsymbol{P}_{\boldsymbol{L A}}$ and if no, modified the design.

Step 8 . Dispay arrester specification.

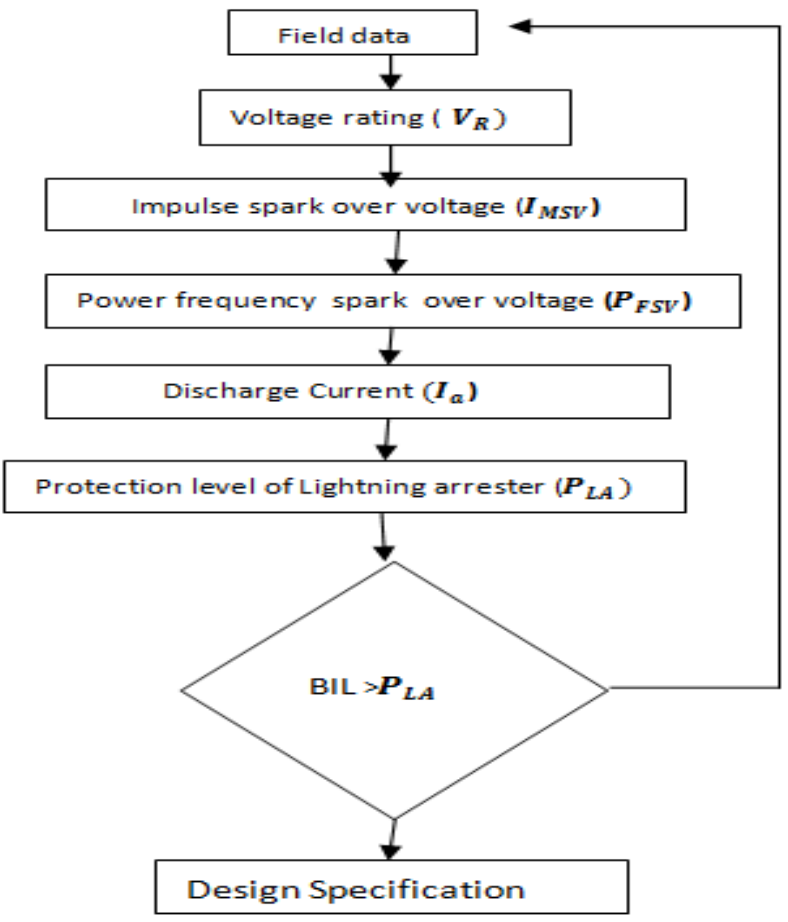

fig:2 Flowchart of Arrester Selection 


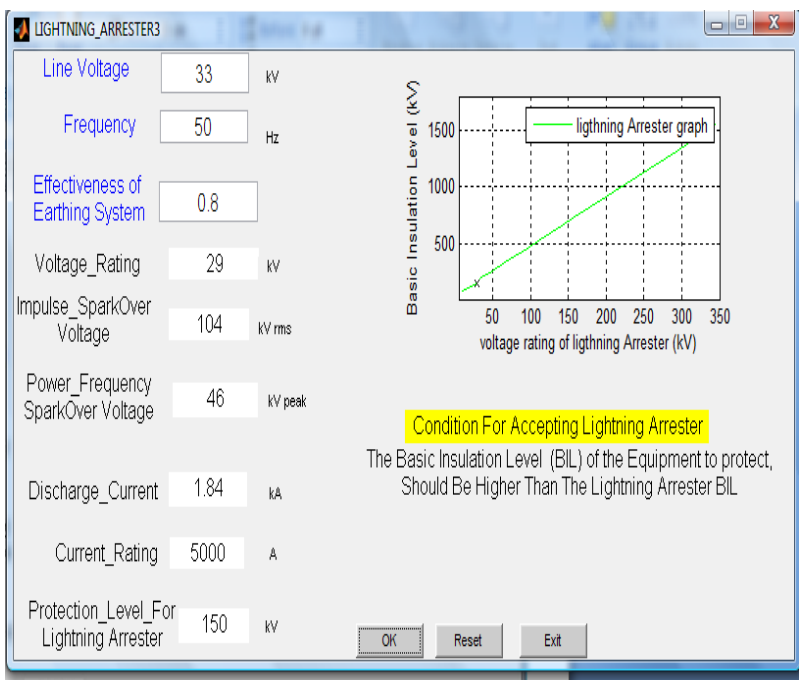

Fig:3 Computer Based Model of Lightning Arrester Selection for 33kV Outgoing Side

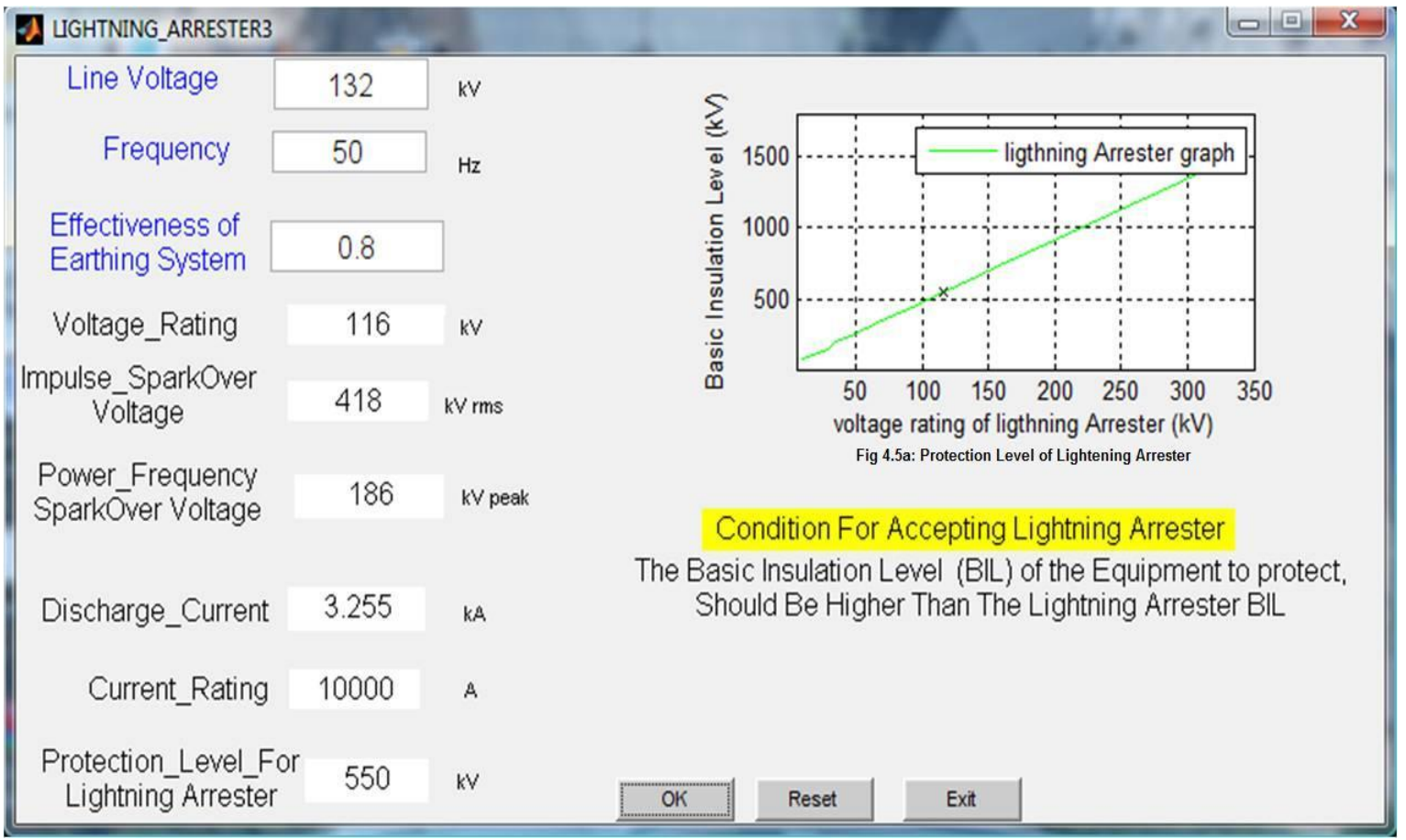

Fig:4 Computer Based Model of Lightning Arrester Specification for $132 \mathrm{kV}$ Incoming Side

Figure 3 and 4 above shows a model, design with help of GUI a sub program of MATLAB program. It an interphase between the computer screen and the program written using MATLAB. From figure 3 and 4, line voltage, frequency and effectiveness of earthing system comes as the input. The Ok button is clicked. The values of the following: Voltage Rating, Impulse Spark Over Voltage , Power Frequency Spark Over Voltage, Peak Discharge Current, Current Rating and Protection level for lightning arrester are displayed. The graph shows the relationship between basic insulation level $\mathrm{kV}$ against the Voltage rating of lightning arrester $\mathrm{kV}$. The reset button when click prepared the model for determine of another arrester specification.

\section{CONCLUSION}

This paper has focus on the design of a computer based model for the selection of lightning arrester for different lines. The results for the specifications, are obtain by Matlab GUIs program. The rated voltages of arresters are $116 \mathrm{kV}$ and $29 \mathrm{kV}$, Impulse spark over voltages are $418 \mathrm{kVrms}$ and $104 \mathrm{kVrms}$, Power frequence spark over voltages are $186 \mathrm{kVpeak}$ and $46 \mathrm{kVpeak}$, the maximum discharge current are $10 \mathrm{kA}$ and $5 \mathrm{kA}$ respectively. The lightning arrester specified in this paper is provided for overvoltage protection in a $132 / 33 \mathrm{kV}$ transmission substation with the transformer basic insulation level of $650 \mathrm{kV}$ on $132 \mathrm{kV}$ side and $170 \mathrm{kV}$ on $33 \mathrm{kV}$ side. 


\section{REFERENCES}

[1] Nay,K.H.(2008): Analysis and Design Selection of Lightning Arrester for Distribution Substation. World Academy of Science, Engineering And Technology Vol.48, pp174-178,2008.

[2] Jude, H.(2005): Lightning Arrester,A Guide to Selection and Application.- GE Publication No.FETA$100 \mathrm{~A}$

[3] Xi Jin,Wei Lu and Shouju, C. (2004): New Type Lightning Protection Scheme of Substation Incoming Lines and Their Simulations. International Conference on power system Technology, Singapore, 21-24 Nov. 2004.

[4] larry, P.,(2010):The application and selection of Lightning Arrester. G.E publication 